\title{
Alterations of Myocardial Amino Acid Metabolism in Chronic Ischemic Heart Disease
}

\author{
Gilbert H. Mudge, Jr., Roger M. Mills, Jr., Heinrich Taegtmeyer, \\ RiCHARD GoRLiN, and MiCHAEL LESCH \\ From the Cardiovascular Division, Department of Medicine, Peter Bent Brigham Hospital, \\ Harvard Medical School, Boston, Massachusetts 02115
}

\begin{abstract}
A B S T R A C T Arteriovenous differences (A-V) of all naturally occurring amino acids, lactate, and oxygen were measured simultaneously with coronary sinus blood flow (CSBF) in 8 normal subjects and 11 patients with coronary artery disease at rest and during pacing stress. Mean values for $\mathrm{CSBF}$ and myocardial oxygen consumptions $\left(\mathrm{MVO}_{2}\right)$ for the two groups were similar at rest and during pacing, although mean $\mathrm{CSBF}$ and $\mathrm{MVO}_{2}$ increased significantly in both groups in the paced as compared to the rest state.
\end{abstract}

Alanine (ala) was the only amino acid released by the myocardium, while only glutamic acid (glu) demonstrated uptake. Mean $\mathrm{A}-\mathrm{V}$ ala was negative at rest in the control and coronary disease groups $(-4.8 \pm 3.8$ vs. $-22.0 \pm 3.0 \mathrm{nmol} / \mathrm{ml}$, respectively), but was significantly more negative in the coronary group $(P<0.001)$ and not statistically different than zero in the normals. A-V ala became significantly negative with pacing in the normals $(-10.0 \pm 4.3 \mathrm{nmol} / \mathrm{ml})$, remained unchanged in the coronary group $(-23.0 \pm 2.9 \mathrm{nmol} / \mathrm{ml})$, and was significantly more negative in the coronary group $(P<0.05)$. Calculation of data on the basis of net ala flux $([\mathrm{A}-\mathrm{V}] \times[\mathrm{CSBF} \times$ hematocrit $])$ yielded similar results as that obtained with $\mathrm{A}-\mathrm{V}$ differences.

A-V glu was significantly positive in normals $(27.7$ $\pm 8.9 \mathrm{nmol} / \mathrm{ml}, P<0.01)$ and coronary patients $(59.9$ $\pm 8.9 \mathrm{nmol} / \mathrm{ml}, P<0.01)$ at rest but significantly greater in the latter group $(P<0.001)$. With pacing, $\mathrm{A}-\mathrm{V}$ glu remained significantly greater than zero in coronary patients $(35.3 \pm 6.3 \mathrm{nmol} / \mathrm{ml})$ and decreased to zero in the normals $(4.3 \pm 11.8 \mathrm{nmol} / \mathrm{ml})$. Calculation of net glu flux

Dr. Gorlin's present address is Mt. Sinai Hospital, New York 10029.

Dr. Lesch is an Established Investigator of the American Heart Association.

Address reprint requests to Dr. M. Lesch, Department of Medicine, Northwestern University, Chicago, Ill. 60611.

Received for publication 10 March 1976 and in revised form 20 July 1976. $(\mathrm{nmol} / \mathrm{min})$ at rest yielded data similar to that based on A-V difference. With pacing, net glu flux in the coronary patients did not decrease due to the augmentation of CSBF.

No relation between $A-V$ glu or ala and CSBF, $\mathrm{MVO}_{2}$, or A-V lactate was noted. The data demonstrate that specific alterations of myocardial amino acid metabolism characterize patients with chronic ischemic heart disease.

\section{INTRODUCTION}

Transaminase reactions which catalyze the conversion of pyruvate to alanine and $\alpha$-ketoglutarate to glutamic acid are recognized as major metabolic branch points linking amino acid and carbohydrate metabolism (1,2). Alanine, glutamine, and glutamic acid are the only amino acids either taken up (glutamate) or released (alanine and glutamine) by human skeletal muscle (3-5) and thus appear to possess unique metabolic roles in normal oxygenated striated muscle. Pyruvate has been identified as the probable source of the three carbon fragment from which alanine is produced in human skeletal muscle, and glutamic acid has been postulated as the source of amino nitrogen for the transamination reaction (6-9).

Evidence suggesting a central metabolic function for alanine and glutamic acid in oxygen-deprived tissue comes from studies which demonstrate alanine accumulation $(7,10-14)$ and glutamate depletion (10, 13-15) during periods of anaerobic metabolism in mammalian tissue.

These observations, suggesting the hypothesis that chronic or repetitive bouts of myocardial ischemia may induce alterations in myocardial amino acid metabolism, prompted the present investigation. In this study, amino acid flux across the normal and ischemic human heart was studied at rest and during pacing. The data obtained demonstrate that specific 
TABLE I

Clinical Data

\begin{tabular}{clll}
\hline Patient no. & \multicolumn{1}{c}{ Diagnosis } & Age & Sex \\
\hline & & $y r$ & \\
1 & Normal & 46 & $\mathrm{M}$ \\
2 & Normal & 48 & $\mathrm{M}$ \\
3 & Normal & 43 & $\mathrm{~F}$ \\
4 & Normal & 36 & $\mathrm{M}$ \\
5 & Normal & 49 & $\mathrm{~F}$ \\
6 & Normal & 34 & $\mathrm{~F}$ \\
7 & Normal & 51 & $\mathrm{~F}$ \\
8 & Normal & 60 & $\mathrm{~F}$ \\
9 & 2 VD & 46 & $\mathrm{M}$ \\
$10^{*}$ & 3 VD & 63 & $\mathrm{M}$ \\
$11^{*}$ & 3 VD & 58 & $\mathrm{~F}$ \\
$12^{*}$ & 2 VD & 61 & $\mathrm{M}$ \\
$13^{*}$ & 3 VD & 39 & $\mathrm{M}$ \\
14 & 2 VD & 38 & $\mathbf{M}$ \\
15 & Isolated LAD & 46 & $\mathrm{M}$ \\
$16^{*}$ & 2 VD & 48 & $\mathrm{M}$ \\
$17^{*}$ & 3 VD & 45 & $\mathrm{~F}$ \\
$18^{*}$ & Isolated LCF & 52 & $\mathbf{M}$ \\
19 & 2 VD & 55 & $\mathbf{M}$ \\
\hline
\end{tabular}

Salient clinical data describing the 8 normal (nos. 1-8) and 11 coronary disease patients (nos. 9-19) are tabulated. Abbreviations used in the coronary group denote the arteriographic diagnosis, with LAD and LCF referring to left anterior descending and left circumflex artery, respectively, and 2 VD or 3 VD indicating two or three vessel disease.

* Patients who developed angina with pacing stress.

alterations of glutamate and alanine flux characterize the heart of patients with chronic coronary artery disease in both the rest and paced state. The fact that these differences were found at rest and not only during pacing induced ischemia suggests that chronic and (or) repetitive episodes of myocardial ischemia may induce specific adaptations of myocardial amino acid metabolism.

\section{METHODS}

Patient selection. 18 patients with chest pain syndromes who were to undergo routine diagnostic catheterization and angiography constituted the study group. Informed consent was obtained from all. Patients with diabetes mellitus or those receiving digitalis glycosides were excluded.

Study protocol. Studies were performed after an overnight fast. The study protocol was initiated before diagnostic catheterization and angiography, since wide fluctuation in the plasma level of numerous amino acids was found after the intracardiac injection of angiographic dye. An arterial catheter was introduced percutaneously into either a brachial or femoral artery and a thermodilution pacing catheter, as described by Ganz et al. (16), was placed in the coronary sinus via a venous cutdown in the left antecubital fossa. The position of the thermodilution catheter was maintained constant throughout the study period as determined by fluoroscopy.

With the patient in the resting state, coronary sinus blood flow was measured with thermodilution technique, and arterial and coronary venous samples were concurrently drawn for oxygen, lactate, and amino acid analysis. Coronary sinus pacing was then initiated and the pacing rate increased incrementally until angina pectoris or atrioventricular block occurred or a rate of 140 beats $/ \mathrm{min}$ was obtained. Pacing was continued for $3 \mathrm{~min}$ once a pacing end point had been reached, coronary sinus blood flow again measured, and transmyocardial blood samples drawn for repeat oxygen, lactate, and amino acid analysis while the paced rate was maintained for an additional $60-90 \mathrm{~s}$.

Biochemical determinations. Lactate and oxygen determinations were performed with previously described techniques $(17,18)$. Arterial and venous blood was collected in heparinized syringes for amino acid analysis. The heparinized samples were immediately placed into ice and centrifuged at $2,000 \mathrm{~g}$ for $15 \mathrm{~min}$ at $4^{\circ} \mathrm{C}$ within $30 \mathrm{~min}$ of collection. The plasma was decanted and plasma proteins precipitated by the addition of crystalline sulfosalicylic acid to a final concentration of $5 \%(\mathrm{wt} / \mathrm{vol})$. The acidified plasma was centrifuged at $4,000 \mathrm{~g}$ for $20 \mathrm{~min}$ at $4^{\circ} \mathrm{C}$ to sediment the precipitated protein. The protein-free plasma extract was quickly frozen, stored at $-20^{\circ} \mathrm{C}$, and analyzed for amino acid content within 14 days.

The content of acidic, neutral, and basic amino acids was quantitatively determined by the method of Stein and Moore (19) as modified by Benson and Patterson (20). Analyses were performed on two columns with a Beckman 119 Automatic Amino Acid Analyzer (Beckman Instruments, Inc., Fullerton, Calif.) using a sodium citrate buffer system. Internal standards were used in each sample and consisted on norleucine or $\alpha$-amino, $\beta$-guanidino proprionic acid for the acidic-neutral and basic amino acids, respectively. Data for glutamine and asparagine are not reported because these compounds are not adequately separated by the methodology employed.

The glutamic acid content of acidified protein free plasma is known to increase slowly with time in the frozen state due to the deamidation of glutamine (19). Pozefsky and Tancredi (9) have demonstrated that if chromatography of a corresponding arterial and venous sample are performed on the same day, no significant error in calculated arteriovenous differences for glutamate is introduced due the the deamidation because the conversion rate for both arterial and venous samples is identical. To confirm this observation, two sets of arterial and venous bloods were chromatographed on three separate occasions $1 \mathrm{mo}$ apart in our laboratory. Absolute glutamate levels increased as expected, but the calculated arteriovenous difference did not change significantly with time.

Statistical analysis. Data were analyzed with Student's $t$ test (21). The $t$ test for nonpaired variables was utilized when comparing intergroup differences while data comparing rest and pace values within a single group were analyzed with the $t$ test for paired variables.

\section{RESULTS}

Clinical data. Table I describes the salient clinical features of the subjects studied. 8 patients were found to have normal coronary anatomy and 11 patients had severe coronary disease. The normal subjects ranged in age from 34 to $64 \mathrm{yr}$ with a mean age of $45.8 \mathrm{yr}$ 
TABLE II

Individual and Mean Values for $\mathrm{CSBF}, \mathrm{MVO}_{2}$, and Arteriovenous Lactate Values in Normal and Coronary Disease Patients

\begin{tabular}{|c|c|c|c|c|c|c|c|}
\hline \multirow[b]{2}{*}{ Group) } & \multirow{2}{*}{$\begin{array}{l}\text { Patient } \\
\text { no. }\end{array}$} & \multicolumn{2}{|c|}{ CSBF } & \multicolumn{2}{|c|}{$\mathrm{MVO}_{2}$} & \multicolumn{2}{|c|}{$\begin{array}{c}\text { Arteriovenous } \\
\text { lactate difference }\end{array}$} \\
\hline & & $\mathrm{R}$ & $\mathrm{P}$ & R & $\mathrm{P}$ & $\mathrm{R}$ & $P$ \\
\hline & & \multicolumn{2}{|c|}{$\mathrm{ml} / \mathrm{min}$} & \multicolumn{2}{|c|}{$\mathrm{ml} / \mathrm{min}$} & \multicolumn{2}{|c|}{ mmol/liter } \\
\hline \multirow[t]{10}{*}{ Normal } & 1 & 90 & 118 & 10.8 & 13.2 & - & - \\
\hline & 2 & 97 & 200 & 12.5 & 23.1 & +.23 & +.16 \\
\hline & 3 & 134 & 157 & 9.6 & 11.2 & +.08 & +.17 \\
\hline & 4 & 166 & 212 & 22.3 & 26.3 & +.24 & +.23 \\
\hline & 5 & 107 & 156 & 8.7 & 12.8 & +.12 & +.16 \\
\hline & 6 & 164 & 219 & 17.2 & 20.2 & .00 & +.01 \\
\hline & 7 & 100 & 116 & 13.3 & 15.4 & +.03 & .00 \\
\hline & 8 & 130 & 156 & - & - & - & - \\
\hline & Mean & 124 & 167 & 13.5 & 17.5 & +0.11 & +0.12 \\
\hline & \pm SEM & \pm 11 & \pm 14 & \pm 1.8 & \pm 2.2 & \pm 0.04 & \pm 0.04 \\
\hline \multirow{13}{*}{$\begin{array}{c}\text { Coronary } \\
\text { disease } \\
\text { patients }\end{array}$} & 9 & 75 & 167 & 7.41 & 16.5 & +0.02 & -0.04 \\
\hline & 10 & 179 & 206 & 24.2 & 27.6 & +0.18 & -0.05 \\
\hline & 11 & 152 & 134 & 16.3 & 14.6 & -0.22 & 0.00 \\
\hline & 12 & 92 & 128 & 10.0 & 14.0 & 0.00 & -0.13 \\
\hline & 13 & 78 & 205 & 7.0 & 18.7 & +0.09 & -0.18 \\
\hline & 14 & 169 & 180 & 18.8 & 18.4 & +0.07 & +0.17 \\
\hline & 15 & 193 & 182 & 20.8 & 18.2 & +0.11 & +0.11 \\
\hline & 16 & 131 & 179 & 14.1 & 21.5 & +0.28 & -0.19 \\
\hline & 17 & 194 & 262 & 23.5 & 31.5 & +0.22 & -0.08 \\
\hline & 18 & 89 & 219 & 10.4 & 20.5 & +0.03 & +0.04 \\
\hline & 19 & 46 & 111 & 5.7 & 13.1 & 0.00 & 0.00 \\
\hline & Mean & 127 & 179 & 14.4 & 19.5 & +0.08 & -0.01 \\
\hline & \pm SEM & \pm 16 & \pm 13 & \pm 2.0 & \pm 1.7 & \pm 0.04 & \pm 0.04 \\
\hline
\end{tabular}

Individual and mean \pm SEM values for coronary sinus blood flow, myocardial oxygen consumption, and arteriovenous lactate values in normal and coronary disease patients are tabulated for the rested $(\mathrm{R})$ and paced $(\mathrm{P})$ state. The mean coronary sinus blood flow noted at rest or during pacing in the normals (nos. 1-8) did not differ significantly from that noted in the coronary group (nos. 9-19). The increment in coronary sinus blood flow noted in each group with pacing was significant $(P<0.01)$. Mean myocardial oxygen consumption during pacing in the normals (nos. 1-8) did not differ significantly from that noted in the coronary group (nos. 9-19). The increment in myocardial oxygen consumption noted in each group with pacing was significant $(P<0.01)$.

and the coronary artery disease group ranged from 38 to $63 \mathrm{yr}$ with a mean of $49.2 \mathrm{yr}$. A preponderance of females $(62.5 \%)$ was noted in the normal group, while only $18 \%$ of the coronary disease group was female. All patients in the coronary disease group had major obstructive lesions ( $>75 \%$ occlusion) in two or three vessels, except two patients each with isolated disease confined to the left anterior descending or left circumflex coronary artery. Patients with disease isolated to the right coronary artery were excluded from the study. Seven patients with coronary disease experienced angina with pacing. In the four patients with coronary disease who did not experience angina with pacing tachycardia, heart block developed at pacing rates ranging from 107 to 133 .

Coronary sinus blood flow, myocardial oxygen consumption, and lactate metabolism. Coronary sinus blood flow (CSBF), ${ }^{1}$ myocardial oxygen consumption $\left(\mathrm{MVO}_{2}\right)$, and myocardial arteriovenous lactate differences at rest and during pacing in both patient groups are summarized in Table II. Measurement of total coronary blood flow or $\mathrm{MVO}_{2}$ did not distinguish the coronary artery disease group from the nor-

\footnotetext{
${ }^{1}$ Abbreviations used in this paper: CSBF, coronary sinus blood flow; $\mathrm{MVO}_{2}$, myocardial oxygen consumptions.
} 
TABLE III

Mean Transmyocardial Arteriovenous Amino Acid Differences ( $\mathrm{nmol} / \mathrm{ml}$ ) at Rest and during Pacing

\begin{tabular}{lccccc}
\hline & \multicolumn{2}{c}{ Normals } & & \multicolumn{2}{c}{ Coronary artery disease } \\
\cline { 2 - 3 } \cline { 5 - 6 } Amino acid & Rest & Pace & & Rest & Pace \\
\hline Threonine & $+1.86 \pm 0.9$ & $-4.3 \pm 2.6$ & & $-1.1 \pm 2.4$ & $-3.8 \pm 1.5$ \\
Serine & $-1.4 \pm 1.9$ & $-1.7 \pm 4.8$ & & $+5.5 \pm 5.1$ & $-0.5 \pm 3.9$ \\
Proline & $.0 \pm 1.0$ & $0 \pm 3.9$ & & $-6.4 \pm 11.4$ & $0.0 \pm 6.8$ \\
Glutamic acid & $+27.7 \pm 8.9 *$ & $+4.3 \pm 1.8$ & & $+59.0 \pm 8.9^{*}$ & $+35.3 \pm 6.3^{*}$ \\
Citrulline & $+2.7 \pm 0.9$ & $-1.1 \pm 2.2$ & & $+0.2 \pm 1.3$ & $-1.8 \pm 1.8$ \\
Glycine & $+6.4 \pm 2.7$ & $-1.9 \pm 3.5$ & & $-0.7 \pm 3.8$ & $-4.9 \pm 4.0$ \\
Alanine & $-4.8 \pm 3.8$ & $-10.0 \pm 4.3 \pm$ & & $-22.0 \pm 3.0^{*}$ & $-23.6 \pm 3.0^{*}$ \\
Valine & $+5.1 \pm 4.0$ & $+0.6 \pm 3.3$ & & $-1.4 \pm 4.2$ & $-10.5 \pm 6.0$ \\
1/2 Cystine & $+0.7 \pm 4.6$ & $-8.8 \pm 5.5$ & & $+5.8 \pm 6.0$ & $-0.7 \pm 2.0$ \\
Methionine & $-0.4 \pm 0.3$ & $-2.0 \pm 1.0$ & & $-1.8 \pm 0.5$ & $+0.4 \pm 0.5$ \\
Isoleucine & $-0.4 \pm 1.2$ & $-1.7 \pm 1.9$ & & $+0.7 \pm 2.0$ & $+1.5 \pm 1.1$ \\
Leucine & $+6.7 \pm 10.0$ & $+0.6 \pm 3.1$ & & $+13.2 \pm 5.1$ & $+3.0 \pm 3.4$ \\
Tyrosine & $-0.3 \pm 1.5$ & $-4.9 \pm 2.3$ & & $-1.4 \pm 1.8$ & $-1.0 \pm 1.1$ \\
Phenylalanine & $-1.1 \pm 0.4$ & $-2.0 \pm 1.4$ & & $+4.0 \pm 4.1$ & $-1.0 \pm 1.0$ \\
Lysine & $-4.0 \pm 3.0$ & $-4.0 \pm 3.0$ & & $-9.0 \pm 5.0$ & $+4.0 \pm 5.0$ \\
Histidine & $-3.0 \pm 1.0$ & $-3.0 \pm 1.0$ & & $+1.0 \pm 1.0$ & $+1.0 \pm 2.0$ \\
Arginine & $-3.6 \pm 1.7$ & $-3.2 \pm 1.4$ & & $-1.7 \pm 2.0$ & $-0.4 \pm 4.0$ \\
Ornithine & $+1.7 \pm 1.3$ & $-0.6 \pm 1.0$ & $+3.1 \pm 1.0$ & $+2.1 \pm 1.2$ \\
\hline
\end{tabular}

Mean transmyocardial arteriovenous differences for 18 amino acids in the rested and paced state in the 8 normal subjects and 11 patients with coronary artery disease are tabulated. In the normal patients values significantly different than zero were found only for: ${ }^{*}$ glutamic acid at rest $(P<0.001)$ and $\downarrow$ alanine during pacing $(P<0.01)$. In the coronary group values significantly different than zero were found for glutamic acid and alanine in both states $(P<0.001)$ as denoted by $\left({ }^{*}\right)$. All other values are not significantly different than zero.

mal controls with mean values for both measurements being statistically identical in the rest and paced state. Mean values for $\mathrm{CSBF}$ and $\mathrm{MVO}_{2}$ increased significantly in both groups with pacing.

Mean values for arteriovenous lactate differences were positive, indicating lactate extraction at rest and during pacing for the normal patients. Mean lactate values for the coronary group indicated extraction at rest $(+0.08 \pm 0.04 \mathrm{nmol} / \mathrm{ml})$ and production with pacing $(-0.01 \pm 0.04 \mathrm{nmol} / \mathrm{ml})$, although this pattern was not uniform within the group.

Transmyocardial amino acid arteriovenous differences. Mean transmyocardial arteriovenous differences for the basic, acidic, and neutral amino acids in the normal and coronary artery disease groups at rest and during pacing are tabulated in Table III. Values statistically different than zero, indicating either net myocardial uptake or release of a specific amino acid, were found only for alanine and glutamic acid in both groups. No other amino acid was taken up or released by the normal or diseased myocardium in significant amounts.

Comparative patterns of alanine metabolism in normal and coronary artery disease groups. Individual values for transmyocardial alanine arteriovenous difference (nanomoles per milliliter) and net flux (arteriovenous difference $\times$ coronary sinus plasma flow nanomoles per minute) for all subjects are pre- sented in Table IV. Although the mean arteriovenous difference at rest for the normal group was negative $(-4.8 \pm 3.8 \mathrm{nmol} / \mathrm{ml})$, this did not differ significantly from zero, with negative values being recorded in five patients and positive values in the remaining three. In the coronary group, in contrast, all resting values for alanine arteriovenous difference were negative (range -6.0 to $-38.0 \mathrm{nmol} / \mathrm{ml}$ ) with the mean value of -22.0 $\pm 3.0 \mathrm{nmol} / \mathrm{ml}$ differing significantly from zero $(P$ $<0.001)$.

With pacing, no significant change in the arteriovenous difference for the coronary group was noted $(-22.0 \pm 3.0 \mathrm{vs}$. $-23.0 \pm 2.9 \mathrm{nmol} / \mathrm{ml})$, whereas the normal group reverted from no significant uptake or release at rest $(-4.8 \pm 3.0 \mathrm{nmol} / \mathrm{ml})$ to significant release $(-10.0 \pm 4.3 \mathrm{nmol} / \mathrm{ml}, P<0.05)$. Although significant release of alanine was documented during the paced state in the normal group, the difference between the arteriovenous values in the rest and paced state was not statistically significant in this group.

Calculation of net flux data produced results similar to that obtained with arteriovenous differences. The coronary group released significant amounts of alanine at rest $(-1,490 \pm 350 \mathrm{nmol} / \mathrm{min}, P<0.001)$ and during pacing $(-2,320 \pm 410 \mathrm{nmol} / \mathrm{min}, P<0.001)$, although the paced and rest values did not differ statistically. The normal group showed no net flux at rest $(-439$ $\pm 490 \mathrm{nmol} / \mathrm{min})$, a significant negative flux $(-1,101$ $\pm 470 \mathrm{nmol} / \mathrm{min}$ ) during pacing, but no significant difference between rest and paced states.

Significantly greater alanine release was noted in the coronary group as compared to normals at rest and during pacing regardless if calculated as arteriovenous difference or net flux (Table IV). Although net alanine release (expressed in nanomoles per minute) appeared to increase in both groups with pacing, the increments did not achieve statistical significance in either.

Comparative patterns of glutamic acid metabolism in normal and coronary artery disease groups. Transmyocardial glutamic acid arteriovenous differences (nanomoles per milliliter) and values for net flux (nanomoles per minute) are presented in Table IV. The mean arteriovenous difference for the normal group at rest $(27.7 \pm 8.0 \mathrm{nmol} / \mathrm{ml})$ was significantly positive $(P$ $<0.01$ ), although one patient demonstrated glutamate release and a wide range of positive values was found in the remaining patients $(+9$ to $+67 \mathrm{nmol} / \mathrm{ml})$. During pacing, the arteriovenous difference for glutamate decreased or became more negative in each normal subject, with three patients converting from uptake at rest to release with pacing. The decrease in mean arteriovenous glutamate differences for the normal group during pacing was of statistical significance $(P<0.005)$ and of sufficient magnitude that the 
TABLE IV

Individual and Mean Values for Transmyocardial Arteriovenous Alanine and Glutamic Acid Differences and Net Transmyocardial Alanine and Glutamic Acid Flux in Normal and Coronary Disease Patients

\begin{tabular}{|c|c|c|c|c|c|c|c|c|c|}
\hline \multirow[b]{2}{*}{ Group } & \multirow{2}{*}{$\begin{array}{l}\text { Patient } \\
\text { no. }\end{array}$} & \multicolumn{2}{|c|}{$\begin{array}{c}\text { Arteriovenous } \\
\text { alanine difference }\end{array}$} & \multicolumn{2}{|c|}{$\begin{array}{l}\text { Net transmyocardial } \\
\text { alanine flux }\end{array}$} & \multicolumn{2}{|c|}{$\begin{array}{l}\text { Arteriovenous } \\
\text { glutamic } \\
\text { acid difference }\end{array}$} & \multicolumn{2}{|c|}{$\begin{array}{l}\text { Net transmyocardial } \\
\text { glutamic acid flux }\end{array}$} \\
\hline & & $\mathbf{R}$ & $\mathbf{P}$ & $\mathbf{R}$ & $\mathbf{P}$ & $\mathbf{R}$ & $\mathbf{P}$ & $\mathbf{R}$ & $\mathbf{P}$ \\
\hline & & \multicolumn{2}{|c|}{$n \mathrm{~mol} / \mathrm{ml}$} & \multicolumn{2}{|c|}{ nmol/min } & \multicolumn{2}{|c|}{ nmol/ml } & \multicolumn{2}{|c|}{ nmol/min } \\
\hline \multirow[t]{10}{*}{ Normal } & 1 & +11.0 & +8.0 & 550 & 520 & +67.0 & +58.0 & 3,350 & 3,770 \\
\hline & 2 & +1.0 & -30.0 & 53 & $-3,300$ & +22.0 & -44.0 & 1,170 & $-4,840$ \\
\hline & 3 & +9.0 & +4.0 & 783 & 408 & -20.0 & -30.0 & $-1,740$ & $-3,060$ \\
\hline & 4 & -27.0 & -12.0 & $-2,565$ & $-1,450$ & +9.0 & -1.0 & 855 & -121 \\
\hline & 5 & -5.0 & -21.0 & -340 & $-2,100$ & +14.0 & -14.0 & 952 & -140 \\
\hline & 6 & -12.0 & -8.0 & $-1,260$ & $-1,120$ & +38.0 & +27.0 & 3,990 & 3,780 \\
\hline & 7 & -6.9 & -13.0 & -427 & -920 & +58.0 & +11.0 & 3,540 & 781 \\
\hline & 8 & -4.0 & -9.0 & -312 & -850 & +44.0 & +28.0 & 3,430 & 2.630 \\
\hline & Mean & -4.8 & -10.0 & -439 & $-1,100$ & 27.7 & 4.3 & 1,940 & 193 \\
\hline & SEM & \pm 3.8 & \pm 4.3 & \pm 490 & \pm 470 & \pm 8.9 & \pm 11.8 & \pm 745 & $\pm 1,003$ \\
\hline \multirow{13}{*}{$\begin{array}{c}\text { Coronary } \\
\text { disease } \\
\text { patients }\end{array}$} & 9 & -22.0 & -17.0 & $-1,030$ & $-1,770$ & +67.0 & +27.0 & 3,150 & 2,810 \\
\hline & 10 & -13.0 & -35.0 & $-1,240$ & $-3,820$ & +65.0 & +47.0 & 6,180 & 5,120 \\
\hline & 11 & -22.0 & -34.0 & $-1,830$ & $-2,690$ & +111.0 & +59.0 & 9,210 & 4,660 \\
\hline & 12 & -6.0 & -26.0 & -306 & $-1,820$ & +6.0 & -12.0 & 306 & -840 \\
\hline & 13 & -21.0 & -14.0 & -861 & $-1,500$ & +33.0 & +6.0 & 1,350 & 642 \\
\hline & 14 & -31.0 & -11.0 & $-2,980$ & $-1,130$ & +48.0 & +40.0 & 4,610 & 4,120 \\
\hline & 15 & -29.0 & -33.0 & -638 & $-3,760$ & +84.0 & +52.0 & 10,300 & 5,930 \\
\hline & 16 & -33.0 & -11.0 & $-2,380$ & $-1,080$ & +64.0 & +35.0 & 4,610 & 3,430 \\
\hline & 17 & -38.0 & -17.0 & $-3,760$ & $-2,280$ & +67.0 & +45.0 & 6,630 & 6,030 \\
\hline & 18 & -21.0 & -40.0 & $-1,180$ & $-5,520$ & +82.0 & +40.0 & 4,590 & 5,520 \\
\hline & 19 & -9.0 & -17.0 & -240 & $-1,120$ & +25.0 & +22.0 & 675 & 1,450 \\
\hline & Mean & -22.0 & -23.0 & $-1,490$ & $-2,320$ & 59.0 & 35.3 & 4,687 & 3,534 \\
\hline & SEM & \pm 3.0 & \pm 2.9 & \pm 350 & \pm 470 & \pm 8.9 & \pm 6.3 & $\pm 1,030$ & \pm 723 \\
\hline
\end{tabular}

Individual and mean \pm SEM values for transmyocardial arteriovenous alanine and glutamic acid differences and net transmyocardial alanine and glutamic acid flux in the rested (R) and paced $(P)$ state for normal (nos. 1-8) and coronary disease patients (nos. 9-19) are tabulated. Alanine release, arteriovenous difference, was significantly greater in the coronary group as compared to normals in both the rested $(P<0.001)$ and paced $(P<0.05)$ state. Net alanine release, flux, was significantly greater in the coronary group in the rested $(P<0.01)$ and paced $(P<0.05)$ state. Glutamic acid uptake, arteriovenous difference, was significantly greater in the coronary group in both the rested $(P<0.001)$ and paced $(P<0.05)$ state. Net glutamic acid uptake, flux, was significantly greater in the coronary group in the rested $(P<0.05)$ and paced $(P<0.02)$ state.

pacing value $(4.3 \pm 11.8 \mathrm{nmol} / \mathrm{ml})$ was not statistically different from zero.

In contrast, glutamate uptake was noted consistently in all coronary patients at rest and reversed to a negative value in only one patient during pacing. Arteriovenous glutamate values decreased significantly during pacing from $59.0 \pm 8.9$ to $35.3 \pm 6.3 \mathrm{nmol} / \mathrm{ml}$ in this group $(P<0.01)$.

Calculation of net glutamate flux yielded comparative data similar to that obtained with arteriovenous differences with one notable exception. The net flux of glutamate in the coronary group, although lower during pacing $(4,680 \pm 1,030$ vs. $3,530 \pm 720$ $\mathrm{nmol} / \mathrm{min}$ ), was not statistically different in the rest and paced states, in contrast to the comparison obtained between these two states with arteriovenous differences.

Significantly greater glutamate uptake was noted in the coronary disease group as compared to the normal group both at rest and during pacing when calculated as either arteriovenous difference or net flux (Table IV). Although arteriovenous differences decreased significantly with pacing in both groups and the net flux of glutamate was significantly lower in the normal 
paced as compared to the normal rest state, net flux did not decrease significantly during pacing in the coronary group.

\section{DISCUSSION}

Amino acid metabolism in the human heart has not been adequately studied despite the recognized relation between carbohydrate and amino acid metabolism $(1,2)$ and the importance of anaerobic carbohydrate metabolism as a potential energy source in the ischemic heart (22). Carlsten et al. reported that other than for the release of alanine, there is no net uptake or release of amino acids by the human heart (23). Amino acid metabolism in human skeletal muscle is well characterized. In both forearm (9) and leg muscle (7), the release of alanine and glutamine and uptake of glutamate are found. The magnitude of the alanine efflux from skeletal muscle cannot be accounted for by the alanine content of skeletal muscle protein. Accordingly, it was first postulated and subsequently demonstrated that alanine is synthesized de novo in skeletal muscle by the transamination of pyruvate (24).

The purpose of the present investigation was twofold: $(a)$ to determine whether the pattern of transmyocardial amino acid differences resemble those of skeletal muscle, and $(b)$ to test the hypothesis that cardiac amino acid metabolism as defined by arteriovenous difference studies might be altered in chronic ischemic heart disease. Our results indicate that while the pattern of amino acid metabolism in the normal and ischemic human heart is generally similar to that reported for skeletal muscle, differences can be found between normal and coronary disease groups which allow identification of the ischemic heart.

Alanine release from the normal myocardium occurred only during pacing stress and not at rest, whereas the diseased heart released alanine in both states in quantities sufficiently large to statistically differentiate the two groups. The degree of variation in alanine arteriovenous difference within each group was, however, so wide as to preclude the use of this index as a marker for coronary disease in a given individual, although coronary disease seems excluded if myocardial alanine uptake is found.

The pattern of glutamate arteriovenous differences in the diseased and normal heart at rest were qualitatively similar to that of skeletal muscle, i.e., significant uptake of glutamate occurred although uptake in the coronary group was greater than in the normal group to a degree that statistically differentiated the two groups. With pacing, the arteriovenous differences in the normal group decreased to zero, whereas glutamate uptake persisted in the coronary group despite a significant decrease in the arteriovenous difference.

Since arteriovenous difference studies do not provide direct measurements of intracellular tissue levels of specific metabolites, and both alanine and glutamate are known to participate in multiple biochemical reactions (1), any explanations for the observed differences in metabolism of these amino acids in the heart of normal and coronary patients must remain speculative. In autolyzing rabbit heart, early increases in tissue lactate concentration are accompanied by a parallel increase in alanine and decrease in glutamate concentrations (10). Similar data has been reported for anoxic rat liver (14), whereas an increase in alanine but no decrease in glutamate was reported for ischemic rat liver (11). In both the rabbit heart and rat liver, changes in alanine and glutamate concentration induced by oxygen deprivation were blunted by pretreatment of the experimental animals with L-cycloserine, a specific inhibitor of alanine transaminase, indicating that alanine production is related to alanine transaminase activity.

It is therefore suggested that in the presence of high concentrations of tissue lactate, as occurs with oxygen deprivation, pyruvate conversion to lactate is retarded due to the mass action effect of lactate accumulation with subsequent augmentation of glutamate-pyruvate transamination. This might result in a net reduction in the concentration of three carbon carbohydrate fragments accumulating in the form of lactate from glycolysis, although the amount of alanine release found cannot account stoichiometrically for the amount of lactate generated during pacing ischemia (Tables II and IV). Biochemical evidence suggesting the possibility of this reaction scheme comes from studies of oxygen deprived and (or) working cardiac and skeletal muscle preparations wherein increases in either pyruvate tissue content or venous efflux were noted (25-29) and the observation that the $K_{m}$ of alanine transaminase for pyruvate decreases with acidosis (30).

The data of Neely et al. (31) and Rovetto et al. (32) in the isolated ischemic rat heart have demonstrated that glycolysis, and therefore the production of high energy phosphate by anaerobic metabolism, was inhibited by the accumulation of lactate. Since this inhibition is not mediated only by mass action effects, but is rather related to specific inhibition of glyceraldehyde phosphate dehydrogenase, small changes in lactate concentration could conceivably relieve this inhibition. This in turn suggests the importance of a mechanism capable of shunting pyruvate derived from glycolysis to alanine and thus decreasing the amount of pyruvate converted to lactate.

The enhanced uptake of glutamate and release of 
alanine noted in the coronary disease group is thus suggestive of a metabolic adaptation of the myocardium to chronic ischemia. The fact that the differences in glutamate and alanine metabolism were present at rest and not just during an acutely induced ischemic state (pacing) supports this hypothesis. Similarly, the observation that glutamate uptake (net flux) decreased with pacing in the normals but was unchanged during pacing in the coronary disease group suggests an alteration of myocardial amino acid metabolism in response to chronic ischemia.

If indeed an adaptation of myocardial metabolism to chronic repetitive ischemia has been demonstrated, previous calculations of the capacity of glycolytic metabolism to generate high energy phosphate in ischemic myocardium based on studies of glycolysis in normal cardiac tissue may be in error (33). Consideration of the possibility that myocardial metabolism in chronic coronary artery disease becomes more efficient in the glycolytic production of high energy phosphate due to adaptive biochemical changes seems warranted.

\section{ACKNOWLEDGMENTS}

This investigation was supported in part by U. S. Public Health Service grants HL 11306 and HL 18033.

\section{REFERENCES}

1. Kaplan, J. H., and H. C. Pitot. 1970. The regulation of intermediary amino acid metabolism in animal tissues. In Mammalian Protein Metabolism. H. N. Munro, editor. Academic Press, Inc., New York. Volume IV. 387443.

2. Safer, B. 1975. The metabolic significance of the malateaspartate cycle in the heart. Circ. Res. 37: 527-533.

3. London, D. R., T. H. Foley, and C. G. Webb. 1965. Evidence for the release of individual amino acids from resting human forearm. Nature (Lond.). 208: 588-589.

4. Pozefsky, T., P. Felig, J. D. Tobin, J. S. Soeldner, and G. F. Cahill, Jr. 1969. Amino acid balance across tissues of the forearm in postabsorptive man. Effects of insulin at two dose levels. J. Clin. Invest. 48: 22732282.

5. Marliss, E. B., T. T. Aoki, T. Pozefsky, A. S. Most, and G. F. Cahill, Jr. 1971. Muscle and splanchnic glutamine and glutamate metabolism in postabsorptive and starved man. J. Clin. Invest. 50: 814-817.

6. Felig, P., T. Pozefsky, E. Marliss, and G. F. Cahill, Jr. 1970. Alanine: key role in gluconeogenesis. Science (Wash. D. C.). 167: 1003-1004.

7. Felig, P., and J. Wahren. 1971. Amino acid metabolism in exercising man. J. Clin. Invest. 50: 2703-2714.

8. Felig, P. 1973. The glucose-alanine cycle. Metab. Clin. Exp. 22: 179-207.

9. Pozefsky, T., and R. G. Tancredi. 1972. Effects of intrabrachial arterial infusion of pyruvate on forearm tissue metabolism. Interrelationship between pyruvate, lactate, and alanine. J. Clin. Invest. 51: 2359-2369.

10. Taegtmeyer, H., and M. Lesch. 1975. Assessment of pro- teolysis in autolyzing rabbit myocardium. Circulation. 52 (Suppl II): 129 (Abstr.)

11. Brosnan, J. T., H. A. Krebs, and D. H. Williamson. 1970. Effects of ischaemia on metabolite concentrations in rat liver. Biochem. J. 117: 91-96.

12. Hochachka, P. W., T. G. Owen, J. F. Allen, and G. C. Whittow. 1975. Multiple end products of anaerobiosis in diving vertebrates. Comp. Biochem. Physiol. 50B: $17-22$.

13. Gailis, L., and E. Benmouyal. 1973. Endogenous alanine, glutamate, aspartate, and glutamine in the perfused guineapig heart: Effect of substrates and cardioactive agents. Can. J. Biochem. 51: 11-20.

14. Williamson, D. H., D. Lopes-Vieira, and B. Walker. 1967. Concentrations of free glucogenic amino acids in livers of rats subjected to various metabolic stresses. Biochem. J. 104: 497-502.

15. Edington, D. W., G. R. Ward, and W. A. Saville. 1973. Energy metabolism of working muscle: Concentration profiles of selected metabolites. Am. J. Physiol. 224: 1375-1380.

16. Ganz, W., K. Tamura, H. S. Marcus, R. Donoso, S. Yoshida, and H. J. C. Swan. 1971. Measurement of coronary sinus blood flow by continuous thermodilution in man. Circulation 44: 181-195.

17. Horn, H. D., and F. H. Bruns. 1956. Quantitative Bestimmung von $L(+)$-Milchsäure mit Milchsäuredehydrogenase. Biochim. Bipohys. Acta. 21: 378-380.

18. Stainsby, W. N., J. T. Fales, and J. L. Lillienthal, Jr. 1955. A rapid spectrophotometric method for determining oxygen content of dog's blood. J. Appl. Physiol. 7: 577-579.

19. Stein, W. H., and S. Moore. 1954. The free amino acids of human blood plasma. J. Biol. Chem. 211: 915-926.

20. Benson, J. V., Jr. and J. A. Patterson. 1965. Accelerated chromatographic analysis of amino acids commonly found in physiological fluids on a spherical resin of specific design. Anal. Biochem. 13: 265-280.

21. Snedecor, G. W. 1956. Statistical methods applied to experiments in agriculture and biology. Iowa State College Press, Ames, Iowa. 5th edition. 45-65.

22. Opie, L. H. 1970. The glucose hypothesis: Relation to acute myocardial ischaemia. J. Mol. Cell. Cardiol. 1: $107-115$.

23. Carlsten, A., B. Hallgren, R. Jagenburg, A. Svanborg, and L. Werkö. Myocardial metabolism of glucose, lactic acid, amino acids and fatty acids in healthy individuals at rest and at different work loads. Scand. J. Clin. Invest. 13: 418-428.

24. Felig, P., and J. Wahren. 1975. Fuel homeostasis in exercise. N. Engl. J. Med. 293: 1078-1084.

25. Neely, J. R., R. M. Denton, P. J. England, and P. J. Randle. 1972. The effects of increased heart work on the tricarboxylate cycle and its interactions with glycolysis in the perfused rat heart. Biochem. J. 128: $147-159$.

26. Opie, L. H. K. R. L. Mansford, and P. Owen. 1971. Effects of increased heart work on glycolysis and adenine nucleotides in the perfused heart of normal and diabetic rats. Biochem. J. 124: 475-490.

27. Williamson, J. R. 1966. Glycolytic control mechanisms. II. Kinetics of intermediate changes during the aerobicanoxic transition in perfused rat heart. J. Biol. Chem. 241: 5026-5036.

28. Owen, P., M. Thomas, V. Young, and L. Opie. 1970. Comparison between metabolic changes in local venous 
and coronary sinus blood after acute experimental coronary arterial occlusion. Am. J. Cardiol. 25: 562-570.

29. Opie, L. H., and K. R. L. Mansford. 1971. The value of lactate and pyruvate measurements in the assessment of the redox state of free nicotinamide-adenine dinucleotide in the cytoplasm of perfused rat heart. Eur. J. Clin. Invest. 1: 295-306.

30. Owen, T. G., and P. W. Hochachka. 1974. Purification and properties of dolphin muscle aspartate and alanine transaminases and their possible roles in the energy metabolism of diving mammals. Biochem. J. 143: $541-553$.
31. Neely, J. R., J. T. Whitmer, and M. J. Rovetto. 1975. Effect of coronary blood flow on glycolytic flux and intracellular $\mathrm{pH}$ in isolated rat hearts. Circ. Res. 37: 733-741.

32. Rovetto, M. J., W. F. Lamberton, and J. R. Neely, 1975. Mechanisms of glycolytic inhibition in ischemic rat hearts. Circ. Res. 37: 742-751.

33. Opie, L. H. 1972. Substrate utilization and glycolysis in the heart. In Metabolism of the Hypoxic and Ischaemic Heart. P. Moret and Z. Fejfar, editors. S. Karger, Basel, Switzerland. 2-21. 